\title{
A giant neurofibroma
}

\author{
S Tilakaratne ${ }^{1}$ and $\mathbf{V}$ Jayasinghe $^{2}$
}

Neurofibromatosis type 1 is an autosomal dominant disorder [1]. It is the cutaneous form of neurofibromatosis. Plexiform neurofibromas occur commonly in type 1 neurofibromatosis, but it is not pathognomonic [2,3]. It is an excessive overgrowth of neural tissue in the subcutaneous fat and is common in branches of the fifth cranial nerve. Sarcomatous changes can occur in $2 \%$ of cases. Usually the neurofibromata are small but occasionally they can be massive.

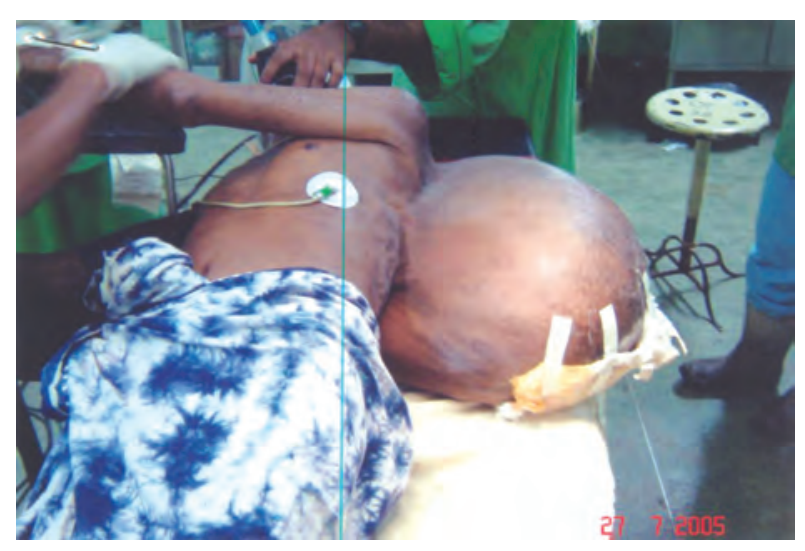

Fig.1. The giant neurofibroma of the back before surgery.
A 57-year old manual worker presented with a large lump hanging from his back (Figure 1). Examination showed multiple neurofibromata and café-au-lait patches suggestive of neurofibromatosis type1. There was a large plexiform neurofibroma on his back. Sheer size of the huge neurofibroma made walking difficult and sleeping uncomfortable for him. There was ulceration of the overlying skin and the patient lost his job due to the difficulty in walking. Excision of the large lump was done under general anaesthesia. Endotracheal intubation was a challenge as the patient was unable to lie supine.

\section{References}

1. Levy P, Viduad D, Leroy K, Laurendeau I, Wechsler J, et al. Molecular profiling of malignant peripheral nerve sheath tumors associated with neurofibromatosis type 1, based on large-scale real-time RT-PCR. Molecular Cancer 2004; 15: 3-20.

2. Endo H, Oikawa A, Utani A, Shinkai H. Plexiform neurofibromas express the transcription factor Glil. Dermatology 2004; 209: 284-7.

3. Lin V, Daniel S, Forte V. Is a plexiform neurofibroma pathognomonic of neurofibromatosis type I? Laryngoscope 2004; 114: 1410-4.

${ }^{1}$ Surgeon, ${ }^{2}$ Registrar in Surgery, Teaching Hospital, Karapitiya, Galle, Sri Lanka. Correspondence: ST, e-mail: <gmathk@sltnet.lk>. (Competing interests: none declared). Received 18 October 2005 and accepted 17 December 2005. 